\title{
ECTOPIC PREGNANCY: A CLINICAL RETROSPECTIVE STUDY
}

\author{
Siddhartha Buragohain'1, Runjun Doley², Bornali Pegu ${ }^{3}$
}

${ }^{1}$ Assistant Professor, Department of Obstetrics and Gynaecology, Jorhat Medical College, Jorhat, Assam, India. ${ }^{2}$ Assistant Professor, Department of Obstetrics and Gynaecology, Jorhat Medical College, Jorhat, Assam, India. ${ }_{3}^{3}$ Registrar, Department of Obstetrics and Gynaecology, Jorhat Medical College, Jorhat, Assam, India.

ABSTRACT
OBJECTIVE
Objective of this study is to determine the incidence, risk factors, mortality, and management of ectopic pregnancy.

\section{METHODOLOGY}

This is a retrospective study done in a tertiary care centre, Jorhat Medical College and Hospital, Assam between January 2014 to April 2016. Analysis of case records of all ectopic pregnancy patients was carried out during this period.

\section{RESULTS}

During the period, a total of 16552 deliveries were recorded of which 123 patients had ectopic gestations accounting for 7.4 per 1000 deliveries. The peak age group was 20-29 years (52.85\%). Most of the patients were multiparous (83.74\%). Commonest risk factors were Pelvic Inflammatory Disease (PID) (43.09\%) and previous abortion (21.95\%). No risk factor was found in $20.33 \%$ of the cases. 99 patients had tubal pregnancy out of which $86.87 \%$ presented with ruptured ectopic. Surgery by laparotomy in the form of unilateral total salpingectomy (67.48\%), partial salpingectomy (20.33\%), salpingostomy (6.50\%), and milking of tube (2.44\%) were the mainstay of management. Two maternal deaths were recorded during the study period.

\section{CONCLUSION}

Ectopic pregnancy can affect any woman in the reproductive age group with or without risk factor. It is not always possible to diagnose a case of ectopic pregnancy in early stage. It requires high index of suspicion. Early diagnosis and timely intervention (Conservative or surgical treatment) will not only help in reducing maternal morbidity and mortality, but also help to preserve the future fertility.

\section{KEYWORDS}

Ectopic Pregnancy, Pelvic Inflammatory Disease, Abortion, Salpingectomy.

HOW TO CITE THIS ARTICLE: Buragohain S, Doley R, Pegu B. Ectopic pregnancy: a clinical retrospective study. J. Evolution Med. Dent. Sci. 2016;5(60):4171-4174, DOI: 10.14260/jemds/2016/952

\section{INTRODUCTION}

An ectopic pregnancy is one in which the fertilised ovum is implanted in a site other than the normal uterine cavity. It is the most important cause of maternal mortality and morbidity in the first trimester. ${ }^{1}$ Ectopic pregnancy presents as an acute emergency and a life-threatening event accounting for up to $10 \%$ of all maternal deaths. ${ }^{2}$ This condition could be considered a public health indicator in developing countries, providing an overall picture of the capacity of health system to deal with the diagnosis and treatment of emergency situations.

During first three months of pregnancy, ectopic pregnancy is the leading cause of maternal morbidity and mortality 3,4 in industrialised countries and possibly the second most frequent cause in developing countries (After abortion-related complications). ${ }^{5}$ Although, the global incidence has been rising during the last three decades. ${ }^{4,6}$ The incidence of the condition varies from country to country depending on the risk factors predominant in the geographical region. In most of Europe and North America, the incidence of ectopic pregnancy has tripled

Financial or Other, Competing Interest: None.

Submission 20-06-2016, Peer Review 14-07-2016,

Acceptance 20-07-2016, Published 26-07-2016.

Corresponding Author:

Dr. Siddhartha Buragohain,

Assistant Professor, Flat $3 A$

Amar Enclave, R. B. Path,

Tarajan, Jorhat-785001, Assam.

E-mail:moon_8b@yahoo.co.in

DOI: $10.14260 /$ jemds $/ 2016 / 952$ over the last 30 years. ${ }^{5}$ Ectopic pregnancy is responsible for thousands of hospital admissions, surgical interventions, and blood transfusions. Moreover, in developing countries, where transport facilities and socio-economic conditions are poor, the diagnosis and interventions are delayed. Majority of the patients are diagnosed after rupture; hence, mortality and morbidity, transfusion requirements, and time of hospital stay are increased.

The main risk factors associated with ectopic pregnancy are previous ectopic pregnancy, previous tubal surgery, documented tubal pathology, in-utero diethylstilbestrol (DES) exposure, previous genital infections (Pelvic inflammatory disease, chlamydia, gonorrhoea), infertility, smoking, current intrauterine device use, and more than one lifetime sexual partners. $^{7}$

\section{MATERIALS AND METHODS}

This study was carried out in the Department of Obstetrics and Gynaecology, Jorhat Medical College and Hospital, a tertiary care centre in upper Assam. Study was done between January 2014 to April 2016. A total number of 123 cases of ectopic pregnancy patients admitted to the hospital were included in this study.

\section{OBJECTIVES OF THE STUDY}

1. To find out the total number of ectopic pregnancy patients in the Department of Obstetrics and Gynaecology, JMCH from January 2014 to April 2016. 
2. To determine the incidence, risk factors, and management of ectopic pregnancy.

3. To study the mortality associated with ectopic pregnancy.

\section{RESULTS}

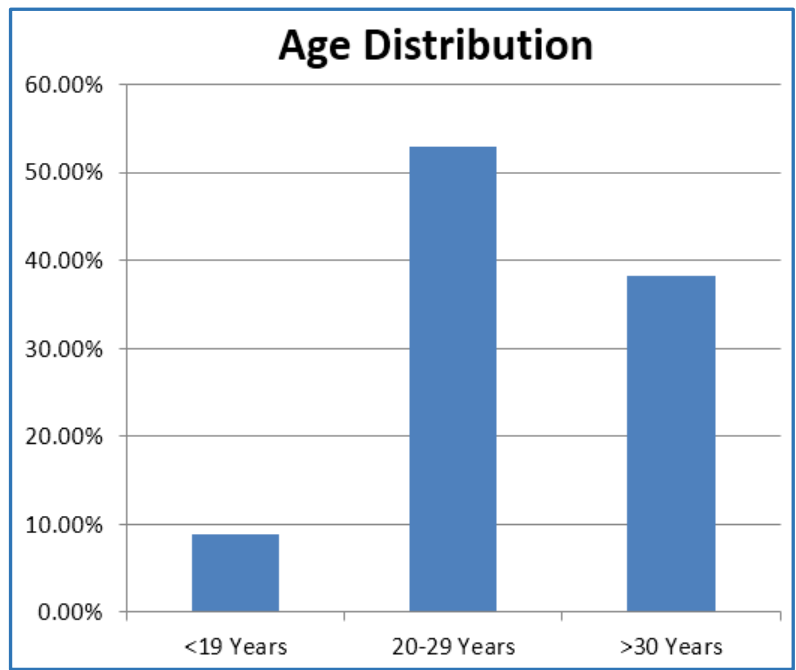

Fig. 1: Age Distribution of Women with Ectopic Pregnancy

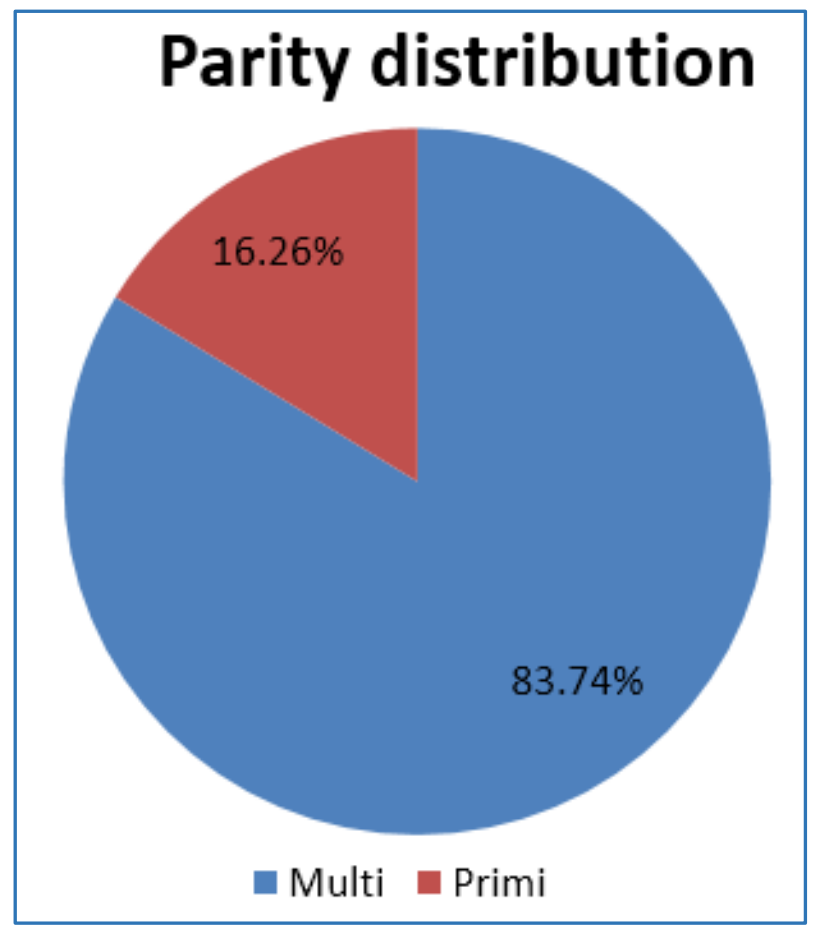

Fig. 2: Distribution of Gravidity Index of Women with Ectopic Pregnancy

During the study period, a total of 16552 deliveries and 123 ectopic gestations recorded. This gives an incidence of $0.74 \%$ of total deliveries. The majority of ectopic gestations, $52.85 \%$ were in the $20-29$ age group (Fig.1). Most patients were multigravidae (83.74\%). Only $16.26 \%$ were primigravidae (Fig. 2).

\begin{tabular}{|c|c|c|}
\hline Risk factor & Number & Percentage \\
\hline Previous Abortion & 27 & 21.95 \\
\hline Previous Tubal Surgery & 1 & 0.81 \\
\hline Previous Ectopic Pregnancy & 1 & 0.81 \\
\hline
\end{tabular}

\begin{tabular}{|c|c|c|}
\hline PID & 53 & 43.09 \\
\hline Infertility Treatment & 3 & 2.44 \\
\hline IUD & 7 & 5.69 \\
\hline Previous LSCS & 6 & 4.88 \\
\hline No Risk Factor & 25 & 20.33 \\
\hline \multicolumn{2}{|c|}{ Table 1: Risk Factor Distribution } \\
\hline
\end{tabular}

The two most common risk factors in the study were: pelvic inflammatory disease (43.09\%) and previous abortions $(21.95 \%)$ and no associated risk factor was found in $20.33 \%$ cases (Table 1).

\begin{tabular}{|c|c|c|}
\hline & Number & Percentage \\
\hline Tubal Pregnancy & 99 & 80.49 \\
\hline Ruptured (a) & 86 & 86.87 \\
\hline Unruptured (b) & 11 & 11.11 \\
\hline Tubal Abortion (c) & 2 & 2.02 \\
\hline Chronic Ectopic & 21 & 17.07 \\
\hline Ovarian & 2 & 1.63 \\
\hline $\begin{array}{c}\text { Pregnancy in } \\
\text { Rudimentary Horn }\end{array}$ & 1 & 0.81 \\
\hline \multicolumn{2}{|c|}{ Table 2: Event Distribution } \\
\hline
\end{tabular}

Tubal pregnancies were the most common (80.49\%). Of these, ruptured tubal ectopic pregnancy was present in $86.87 \%$ on laparotomy, $11.11 \%$ had unruptured tubal pregnancy, and $17.07 \%$ had chronic ectopic pregnancy (Table 2).

\begin{tabular}{|c|c|c|}
\hline Intervention & Number & Percentage \\
\hline Unilateral Total Salpingectomy & 83 & 67.48 \\
\hline Partial Salpingectomy & 25 & 20.33 \\
\hline Salpingostomy & 8 & 6.50 \\
\hline Milking of Tube & 3 & 2.44 \\
\hline $\begin{array}{c}\text { Ovariotomy/Salpingo- } \\
\text { oophorectomy }\end{array}$ & 2 & 1.63 \\
\hline Cornual Resection & 1 & 0.81 \\
\hline Hysterectomy & 1 & 0.81 \\
\hline \multicolumn{2}{|c|}{ Table 3: Surgery } \\
\hline
\end{tabular}

The most common surgeries done were unilateral total salpingectomy $(67.48 \%)$ and partial salpingectomy $(20.33 \%)$. Salpingo-oophorectomy and hysterectomy were done in $1.63 \%$ and $0.81 \%$ respectively.

\section{Mortality}

Two patients were reported dead in the study period, which gives a $1.6 \%$ mortality rate in this study.

\section{DISCUSSION}

The incidence of ectopic pregnancy has followed an increasing trend during the last three decades throughout the world. 6,8 The current study showed a high incidence rate of ectopic pregnancy (7.4 per 1000 deliveries).

In a multicentric case control study in India, the incidence of ectopic pregnancy rate was 3.12 per 1000 pregnancies or 3.86 per 1000 live births. ${ }^{9}$ Shetty SK et al ${ }^{10}$ reported an incidence of 5.6 per 1000 deliveries at Mangalore, Porwal S et al ${ }^{11}$ reported an incidence of 2.46 per 1000 deliveries and Raina A et al $^{12}$ reported an incidence of 16 per 1000 deliveries. 
Gaddagi $\mathrm{R}$ et al ${ }^{13}$ found an incidence of 1:399 pregnancies in Mysore.

Multiparous women (83.74\%) were found to be more prone to ectopic pregnancy, which is close to other studies.10,13,14,15,16 However, there were conflicting results from studies by Majhi et $\mathrm{al}^{4}$ and Raina A et $\mathrm{al}^{12}$, which showed increased risk of ectopic pregnancy in primigravida. Surprisingly, Etuknwa BT et al ${ }^{17}$ reported increased risk of ectopic pregnancy amongst single woman and students than married women.

In our study, maximum number of cases found in the age group of 20-29 years (52.85\%), which is quite similar with results of studies done in India, ${ }^{4,13}$ Nigeria, ${ }^{17}$ Bangladesh, ${ }^{16}$ and Pakistan. ${ }^{14}$ This age group corresponds to the peak sexual activity and age of reproduction.

In this study, PID and history of previous abortion are commonly identified risk factors for ectopic pregnancy. The commonest risk factor was PID (43.09\%). This frequency is almost consistent with previously reported results in literature,14,18,19,20 thus implicating PID as a major factor for ectopic pregnancy. The lack of knowledge on sexual health and trend of early marriages in our society predisposes the young women to Sexually Transmitted Infections (STIs). Rose ${ }^{19}$ reported a 9-fold increased risk of ectopic pregnancy in patients with PID and emphasised the importance of usage of condom. The growing incidence of PID need a preventive strategy. Awareness on safe sexual practice and health education is necessary to prevent STIs. Emphasis should be towards treatment of both partners for complete cure.

Previous abortion was the second common risk factor for ectopic pregnancy found in $21.95 \%$ cases. Similarly, Malathi T et $\mathrm{al}^{21}$ and Mufti $\mathrm{S}$ et $\mathrm{al}^{22}$ had reported history of prior abortion in $28.8 \%$ and $21.05 \%$ respectively. Our finding is also similar to other studies $10,14,16,17$ thus indicating previous abortion as one of the common risk factor of ectopic pregnancy.

Risk factor for ectopic pregnancy could not be identified in $20.33 \%$ women. This result is consistent with other studies. ${ }^{12,14}$ The presence of risk factors can aid in diagnosis of ectopic pregnancy, but it can occur in women even in the absence of any risk factor. About one third of women with an ectopic pregnancy will have no known risk factor (NICE guidelines). ${ }^{23}$

The most common surgeries performed were partial and total salpingectomy $(20.33 \%$ and $67.48 \%$ respectively), salpingo-oophorectomy (1.63\%), and salpingostomy (6.50\%), which are comparable to other studies. ${ }^{10,13,16}$ As medical management needs extremely close followup and hospitalisation, surgical management is still the method of choice in our country. ${ }^{24}$ Laparoscopy and medical therapy have now emerged as the widely used therapeutic modalities with great succession in terms of reduced morbidity, shorter hospital stay, and conservation of fertility. ${ }^{25}$ However, choice depends upon early identification of ectopic pregnancy and stable condition of patients. ${ }^{26}$

Being a tertiary care centre in upper Assam, Jorhat Medical College and Hospital acts as a referral centre for both rural and urban population. So, most of the patients presented with ruptured ectopic. In our study, $80.49 \%$ patients had tubal pregnancy and out of these $86.87 \%$ presented with rupture. Only $11.11 \%$ and $2.02 \%$ patients had unruptured tubal pregnancy and tubal abortion respectively. Gaddagi RA et al ${ }^{13}$ study found $78.3 \%$ had ruptured ectopic, $10.81 \%$ and $8.1 \%$ had tubal abortion and unruptured ectopic respectively. Roussos D et al27 in their study observed that rupture of the tube is more often observed in women with a history of ectopic pregnancy and in women with full-term pregnancy.

Thirteen maternal deaths resulted from ectopic pregnancy in the UK during the period of 1997-1999.26 In our study, there were two maternal deaths, which is comparable to study by Bassey ET et al. ${ }^{17}$ In developing countries, maternal deaths are frequently underreported resulting in the omission of numerous patients who died before receiving any treatment including those who died due to ectopic pregnancy.

\section{CONCLUSION}

PID and history of previous abortion were the main risk factors for ectopic pregnancy. But, it can occur in women even in the absence of any risk factor. Due to lack of early antenatal visit and delay in making diagnosis at early stage, majority of the patients presented at late stage; so, open surgery was required in most of the cases. This emphasises the early diagnosis and prompt conservative surgical or medical management, which will not only help in reducing maternal mortality and morbidity rates, but also go a long way in preservation of future fertility.

\section{REFERENCES}

1. Bhatla N. Jeffcoates principles of gynaecology. chapter11. $6^{\text {th }}$ edn. New Delhi: Arnold 2001;208-224.

2. Kamwendo F, Forslin L, Bodin L, et al. Epidemiology of ectopic pregnancy during a 28 year period and the role of pelvic inflammatory disease. Sex Transm Infect 2000;76(1):28-32.

3. Okunlola MA, Adesina OA, Adekunle AO. Repeat ipsilateral ectopic gestation: a series of 3 cases. Afr J Med Med Sci 2006;35(2):173-5.

4. Majhi AK, Roy N, Karmakar KS, et al. Ectopic pregnancyan analysis of 180 cases. J Indian Med Assoc 2007;105(6)308-12.

5. Thonneau P, Hijazi Y, Goyaux N, et al. Ectopic pregnancy in Conakry, Guinea. Bull World Health Organ 2002;80(5):365-70.

6. Rajkhowa M, Glass MR, Rutherford AJ, et al. Trends in incidence of ectopic pregnancy in England and Wales from 1966-1996. Br J Obstet Gynaecol 2000;107(3): 369-74.

7. Ankum WM, Mol BW, Veen VDF, et al. Risk factors for ectopic pregnancy: a meta-analysis. Fertil Steril 1996;65(6):1093-9.

8. Aral SO. Sexual behaviour as risk factor for sexually transmitted diseases. In: Germaine A, Holmes KK, Piot P, et al. eds. Reproductive tract infections: global impact and priorities for women's reproductive health. New York: Plenum Press 1992:185-91.

9. ICMR. ICMR Task force project: multicentre case control study of ectopic pregnancy in India. J Obstet Gynaecol India 1990;40:425-30.

10. Shetty SK, Shetty AK. A clinical study of ectopic pregnancies in a tertiary care hospital of Mangalore, India. Innovative Journal of Medical and Health Science 2014;4(1):305-9.

11. Gupta R, Porwal S, Swarnkar M, et al. Incidence, trends, and risk factors for ectopic pregnancies in a tertiary care hospital of Rajasthan. JPBMS 2012;16(16):1-4. 
12. Raina A, Bajpai M. Experience with ectopic pregnancy in a hospital in India. Indian Journal of Applied Research 2015;5(4):535-37.

13. Gaddagi RA, Chandrashekhar AP. A clinical study of ectopic pregnancy. Journal of Clinical and Diagnostic Research 2012;6(5):867-9.

14. Shaikh NB, Shaikh S, Shaikh F. A clinical study of ectopic pregnancy. J Ayub Med Coll Abbottabad 2014;26(2):17881.

15. Karki RCL, Pradhan B, Duwa S. Annual analysis of ectopic pregnancy in tertiary care hospital. PMJN 2011;11(1):5-8.

16. Yeasmin S, Uddin MJ, Hasan E. A clinical study of ectopic pregnancies in a tertiary care hospital of Chittagong, Bangladesh. Chattagram Maa-O-Shishu Hospital Medical College Journal 2014;13(3):1-4.

17. Tom EB, Okpara AO, Imo PA, et al. Ectopic pregnancy: a Nigerian urban experience. Korean J Obstet Gynaecol 2012;55(5):309-14.

18. Amoko DH, Buga GA. Clinical presentation of ectopic pregnancy in Transkei, South Africa. East Afr Med J 1995;72(12):770-3.

19. Anorlu RI, Oluwole A, Abudu O0, et al. Risk factors for ectopic pregnancy in Lagos, Nigeria. Acta Obstet Gynaecol Scand 2005;84(2):184-8.

20. Udigwe GO, Umeononihu OS, Mbachu II. Ectopic pregnancy: a 5-year review of cases at Nnamdi Azikiwe University Teaching Hospital, Nnewi. Niger Med J 2010;51(4):160-3.
21. Mufti S, Rather S, Rangrez RA, et al. Ectopic pregnancy: an analysis of 114 cases. JK-Practitioner 2012;17(4):20-3.

22. Malathi T, Kanmani TR, Sowmya K, et al. Ectopic pregnancy-an experience in medical hospital and research institute. International Journal of Scientific Research 2015;4(6):130-2.

23. National Collaborating Centre for Women's and Children's Health commissioned by the National Institute for Health and Clinical Excellence. Ectopic pregnancy and miscarriage: diagnosis and initial management in early pregnancy of ectopic pregnancy and miscarriage. London: RCOG 2012. www.rcog.org.uk.

24. Chatterjee S, Sandip D, Chowdhury RG, et al. Ectopic pregnancy in previously infertile women subsequent pregnancy outcome after laparoscopic management. Al Ameen J Med Sci 2009;2(1):67-72.

25. Jurkovie D. Ectopic pregnancy. In: Edmonds DK, ed. Dewhurst's Textbook of Obstetrics and Gynaecology. $7^{\text {th }}$ edn. USA: Black well Publishers 2007.

26. Shah N, Khan NH. Ectopic pregnancy: presentation and risk factors. J Coll Physicians Surg Pak 2005;15(9):535-8.

27. Roussos D, Panidis D, Matalliotakis I, et al. Factors that may predispose to rupture of tubal ectopic pregnancy. Eur J Obstet Gynaecol Reprod Biol 2000;89(1):15-7. 